\title{
Intrinsic motivated cervical cancer screening intervention framework
}

\author{
Md. Rajib Hasan \\ Auckland University of \\ Technology \\ Auckland, New Zealand \\ mhasan@aut.ac.nz
}

\author{
Hamid \\ Gholamhosseini \\ Auckland University of \\ Technology \\ Auckland, New Zealand \\ hgholamh@aut.ac.nz
}

\author{
Nurul I Sarkar \\ Auckland University of \\ Technology \\ Auckland, New Zealand \\ nurul.sarkar@aut.ac.nz
}

\author{
S M Safiuzzaman \\ Chittagong Medical \\ College Hospital, \\ Chittagong, Bangladesh \\ smsafiuzzaman@gmail.c \\ om
}

\begin{abstract}
Cervical cancer turned into a reason of extreme mortality even though it is preventable. The expansion rate of cervical cancer is at alarming rate internationally, including both developed (e.g. New Zealand) and developing (e.g. Bangladesh) countries. This study considers survey data collected from Chittagong Medical College Hospital in Bangladesh and other secondary data from open sources. Studies have uncovered that younger women aged from 25 to 34 tend not to react to cervical screening program. Without regular cervical cancer screening, the early changes that could progress to cervical cancer suffering would not be picked up. This study aims to address these concerns by proposing a cervical screening intervention program to encourage women of all age group to participate in the screening program. The intervention could contribute to the health sector by decreasing the cervical cancer mortality rate and associated cost. The preliminary investigation shows that about $96 \%$ screening take-up following such intervention program suggesting that a proper intrinsic motivated cervical cancer intervention program is required.
\end{abstract}

Keywords- Cervical cancer; Intervention, mortality, morbity; pap smear; screening.

\section{INTRODUCTION}

Cancer is anticipated to be an inexorably imperative reason for morbidity and mortality in the following couple of decades, in all parts of the world [1]. Cervical cancer is the second most common female tumor worldwide [2] which forms in tissues of a cervix i.e. the lower part of a person's uterus [3]. Early pap smear test may prevent mortality but not all women are willing to receive it in the appropriate time interval [4]. Data from the US National Center for health statistics in 2017 reveals that only $69 \%$ percent had pap smear tests in last three years. Women below 18 years were not interested in pap smear test [5]. The determined changes in population socioeconomic in the following two decades imply that regardless of the possibility that current worldwide disease rates stay unaltered, the evaluated rate of 12.7 million new cancer cases in 2008 will ascend to 21.4 million by 2030 [6].

There are 1.3 to 1.5 million cancer patients in Bangladesh, with around 200,000 patients recently diagnosed to have cancer every year [7]. In the coming years, the expansion in populace and lifespan will bring an increment in the quantity of cancer patients in Bangladesh. At the point when consolidated with populace maturing, the expansion in cancer commonness is unavoidable. Keeping pace with the request will require a noteworthy government sense of duty regarding disease aversion and remedial administrations in the coming years.

In New Zealand, around 160 women develop cervical cancer every year - and around 50 die from it. Every year there are 25,000 strange Pap smear test results among New Zealand women while normal three-yearly cervical cancer tests are prescribed for all women matured 20 to 70 who have ever been sexually active [8]. Without cervical cancer screening, around one out of 90 women would develop cervical cancer and one out of 200 may die from it while with cervical cancer screening, around one out of 570 would develop cervical cancer and one out of 1280 may die from it [9].

Cervical cancer could be exceedingly preventable in many nations because of a wide accessibility of the screening test and immunization to avert human papilloma infection (HPV) disease. HPV is the primary cause of cervical cancer and has been recognized in 90 $100 \%$ of cervical cancer growth incidents [10]. In any case, women are hesitant and reluctant to these cervical screening tests. An individualized intervention framework or structure for proposing cervical cancer screening may urge women to participate in the cervical test and along these lines, the death rate might be lessened. 


\section{PROBLEM}

A few studies suggested that the purpose behind lack of participation in the screening programs could be due to the absence of adequate data or sufficient knowledge or motivation about the cause of this form of cancer. Although numerous community programs and research have been led to urge women to participate at cervical screening programs, often they respond late and therefore desire treatment when the cancer is far advanced, bringing poor outcomes. These generalized cervical cancer screening programs are subsequently not completely used and neglect to accomplish the goal of empowering early detection. Hence, the proposed study aims to analyze factors in an intervention program that fulfills individual needs.

\section{A. An estimation of the sample size}

A cross-sectional study was conducted during FebruaryApril 2009 in rural areas of Dadri Tehsil in Uttar Pradesh. For an expected frequency of $40 \%$ of cervical cancer awareness in the community with $5 \%$ absolute allowable error, 95\% confidence level, and an anticipated 20\% nonresponse level a sample size of 200 was found adequate [11].

\section{B. Previous work}

Utilizing the Garrard (1999) Matrix strategy approach [12], a modified framework was outlined and utilized as a literature study as appeared in Table 1. The method comprised of clear cut segments in which information identified with the author, year of publication, category and issues to cervical cancer counteractive action benefit use. After careful perusing of the article, information identified related cervical cancer issues and were entered into a matrix containing columns reflecting the issue categories. The data description is discussed next.

\section{DATA DESCRIPTION}

For this study, a total of 600 pamphlets/ questionnaires have been distributed throughout the region around the study site and another 400 within the area of the control site in Bangladesh. However, a total of 300 participants responded to the questionnaires so far; 200 from the study site and another 100 from the control site. There was a total of nine questions set in this study. The data are multivariate without any missing value (since the questionnaire is filled by medical doctors and yet not very sensitive personal question involved here). We asked several questions to the participants and the answers were recorded by medical doctors on a weekly basis. The study questionnaire distributed in the period of two months.
Table 1: Summary of literature review from 2012 and 2017.

\begin{tabular}{|c|c|}
\hline References & Issues identified \\
\hline [13] & $\begin{array}{l}\text { Cervical cancer knowledge had a } \\
\text { significantly negative relationship with } \\
\text { barriers to cervical cancer screening. }\end{array}$ \\
\hline$[15]$ & $\begin{array}{l}\text { Awareness and HPV vaccination. } \\
\text { Concerns about the future fertility of the } \\
\text { vaccinated girls. }\end{array}$ \\
\hline$[16]$ & $\begin{array}{l}\text { Age, income, and awareness and cervical } \\
\text { cancer prevention services utilization } \\
\text { among Batswana women. }\end{array}$ \\
\hline$[18]$ & $\begin{array}{l}\text { Cervical cancer remains a significant } \\
\text { cause of mortality in low-income } \\
\text { countries. }\end{array}$ \\
\hline [19] & $\begin{array}{l}\text { American Cancer Society (ACS) } \\
\text { guidelines suggest that initiating } \\
\text { screening at the age of } 21 \text { or } 32 .\end{array}$ \\
\hline$[20]$ & $\begin{array}{l}\text { The burden from disease remains } \\
\text { important because of the difficulty in } \\
\text { implementing in developing countries } \\
\text { due to poverty, lack of healthcare } \\
\text { infrastructures and trained practitioners. }\end{array}$ \\
\hline$[21]$ & $\begin{array}{l}\text { Primary HPV screening with partial } \\
\text { genotyping would be more effective and } \\
\text { less costly than the current cytology- } \\
\text { based screening program in New } \\
\text { Zealand. }\end{array}$ \\
\hline$[22]$ & $\begin{array}{l}\text { Estimate the cost of comprehensive } \\
\text { primary and secondary cervical cancer } \\
\text { preventions in low- and middle-income } \\
\text { countries. }\end{array}$ \\
\hline
\end{tabular}

\section{A. Data collection}

Collecting data about cervical cancer is extremely hard as women are reluctant to reveal the information [23]. However, our data collection process was successful due to the involvement of medical doctor and our approach to the women. For data collection, we have distributed the questionnaire and cervical cancer awareness pamphlet. We asked participants to fill up their name, age, pap smear tests status and request them to participate in cervical cancer awareness programs under the supervision of a medical doctor. The questionnaire and details of the participant remain unrevealed to the public but with a participant identity number (Appendix A - Table 2).

\section{DATA ANALYSIS TOOLS}

Microsoft Excel has been used to keep the record of data and Special Package for Social Scientist (SPSS) has been employed to analysis the data for this study. 


\section{AgE CHARACTERISTICS OF PARTICIPANTS IN CERVICAL CANCER TAKEUP}

The age distribution of the participants in intervention and control areas in the take-up of cervical cancer are appeared in Figure 1. The figure uncovers that $3 \%$ of the participants were beneath age 21 years, $32 \%$ were in the age scope of 21-30 years and 38\% were between 31-40 years. Moreover, around $20 \%$ of the ladies examined were in the age scope of $41-50$ years, $6 \%$ in the scope of 51-60 years and $1 \%$ for the members who were over 60 years. It can likewise be noticed that $93 \%$ of the members were in the conceptive or reproductive age 15-49 years.

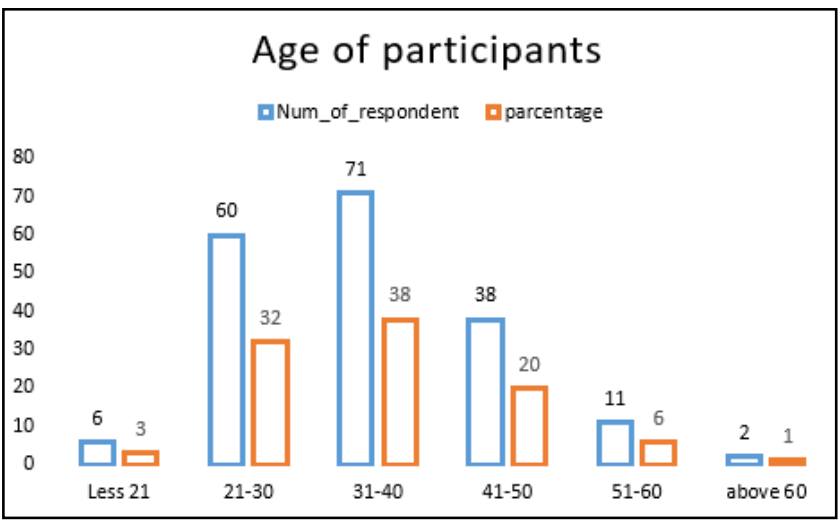

Fig. 1. Age of participants in the uptake of cervical cancer screening.

\section{Pap SMEAR Test Uptake at The Study Site}

The consequence of the Pap smear take-up by women in the study sites in the pre-intervention and amid intervention periods by age groups of women is shown in Fig. 2. The proportion of the number of take-up for each age group to the aggregate in the two-time frames was communicated as a percentage.

Age 21 to 40 years reacted more than some other age groups to the requirements for cervical cancer screening (48\% amid the intervention time frame, and $37 \%$ for the pre-mediation period). The pattern of reaction falls with expanding age. Females over 60 years old once in a while turned out to the call for standard cervical cancer screening. In both the pre-intervention and amid intervention the takeup the example is comparable. Likewise, the total take-up of Pap spread test was higher during the time of intervention (200) than in the pre-intervention period (150).

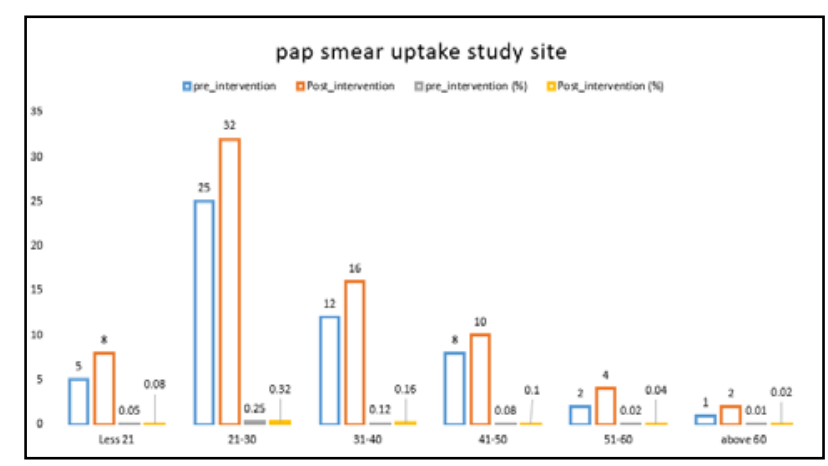

Fig. 2. Percentage Pap Smear Uptake in the study site

Fig. 2 illustrates the percentage of cervical cancer screening take-up by age at the study site.

\section{A. Takeup of Pap smear test at the Study Site by week}

The results of Pap smear test take-up by weeks at the study site is appeared in Figure 3. The trends of Pap smear take-up at the study site throughout the weeks indicates sustained increments in take-up in the intervention weeks more than in the pre-intervention weeks. Similar to the previous analysis, the ratio of the number of take-up for every week to the aggregate $(n=200)$ was expressed as percentage. Starting from the beginning of intervention there was an enduring maintained ascent from $10 \%$ in the first week to $17 \%$ in the eighth week. This pattern of consistent ascent in take-up varies from the fluctuating takeup pattern experienced in the pre-intervention week (two months). This is illustrated in Fig. 3.

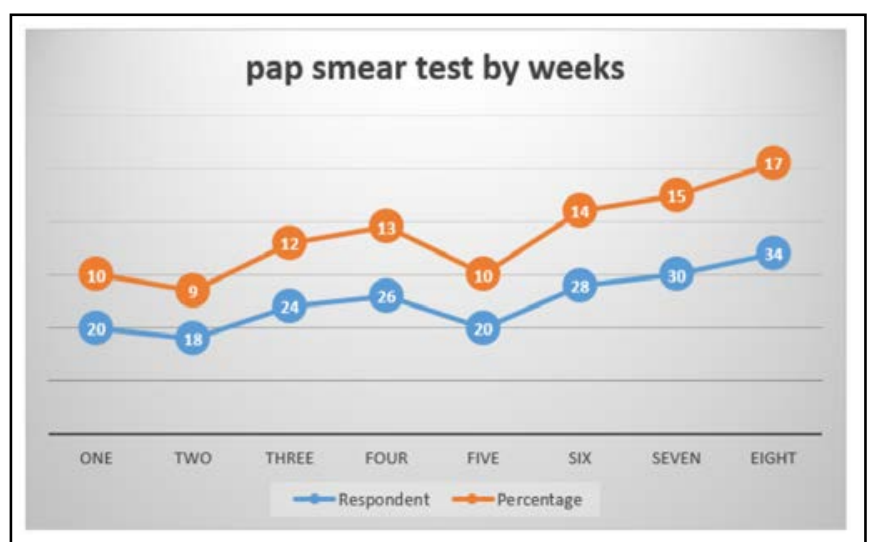

Fig. 3. Uptake of Pap smear test by week at the study site

\section{CONCLUSION}

A few studies that have been led on cervical cancer screening, uncovered distinctive levels of boundaries to inspire women to participate in the screening program. In any case, just a few had an obliged examination concerning the viewpoints that advance reception of cervical cancer screening conduct by individual woman. None has concentrated on the individualized intervention for cervical cancer screening which may help women to distinguish the danger of having cervical cancer. This study is an endeavor 
to support the information reservoir from cervical cancer that will help women (in any countries) in forming attitudes, beliefs, and values responsible for satisfactory cervical cancer screening lifestyle.

\section{ACKNOWLEDGMENT}

We would like to thank Dr. Shariful Hasan, KPJ Ampang Puteri Specialist Hospital, Malaysia for the support of expert system knowledge extraction for medical data understanding.

\section{REFERENCES}

[1] S. A. Hussain and R. Sullivan, "Cancer control in Bangladesh,” Jpn. J. Clin. Oncol., vol. 43, no. 12, pp. 1159-1169, 2013.

[2] I. C. Scarinci et al., "Cervical Cancer Prevention: New Tools and Old Barriers," Cancer, vol. 116, no. 11, pp. 2531-2542, 2011.

[3] Southern Cross Medical Library, "Cervical cancer causes, symptoms, treatment, prevention," 2013. [Online]. Available: https://www.southerncross.co.nz/group/medicallibrary/cervical-cancer-causes-symptomstreatment-prevention. [Accessed: 10-Jul-2017].

[4] R. Chasan, "Cervical Cancer," 2010.

[5] Health United States 2016, "Health, United States, 2016," USA, 2016.

[6] IARC, "Cancer incidence and mortality worldwide," Lyon, 2011.

[7] V. Noronha et al., "A fresh look at oncology facts on south central Asia and SAARC countries," South Asian J. Cancer, vol. 1, no. 1, p. 1, 2012.

[8] Ministry of Health New Zealand, "Cervical screening," 2017. [Online]. Available: http://www.timetoscreen.nz/cervical-screening/. [Accessed: 08-Jul-2017].

[9] Ministry of Health New Zealand, "Cervical cancer," 2014. [Online]. Available: http://www.health.govt.nz/your-health/conditionsand-treatments/diseases-and-illnesses/cervicalcancer. [Accessed: 09-Jul-2017].

[10] K. B. Roland, V. B. Benard, A. Soman, N. Breen, D. Kepka, and M. Saraiya, "Cervical cancer screening among young adult women in the United States.," Am. Assoc. Cancer Res., vol. 22, no. 4, pp. 580-8, 2013.

[11] S. Labani and S. Asthana, "Factors associated with attitudes of rural women toward cervical cancer screening," Indian J. Community Med., vol. 38, no. 4, p. 246, 2013.
[12] Garrard and Judith, Health Sciences Literature Review Made Easy: The Matrix Method. Gaithersburg: Aspen Publishers, 2004.

[13] M. E. Hoque and S. Ghuman, "Cervical cancer screening among university students in South Africa: Atheory based study," Supportive Care in Cancer, vol. 22, no. 1 SUPPL. 1. p. S51, 2014.

[14] Y. Jia et al., "Knowledge about Cervical Cancer and Barriers of Screening Program among Women in Wufeng County, a High-Incidence Region of Cervical Cancer in China," vol. 8, no. 7, pp. 2-8, 2013.

[15] C. Banura and F. M. Mirembe, "Universal routine HPV vaccination for young girls in Uganda: a review of opportunities and potential obstacles," Infect. Agent. Cancer, vol. 7, no. 24, pp. 1-6, 2012.

[16] A. M. Mingo et al., "Cervical Cancer Awareness and Screening in Botswana," Int J Gynecol Cancer, vol. 22, no. 4, pp. 638-644, 2015.

[17] M. J et al., "Effect of socio-economic factors on delayed access to health care among Chinese cervical cancer patients with late rectal complications after radiotherapy.," Oncol. Gynecol., vol. 124, no. 3, pp. 395-398, 2012.

[18] K. Fernandes, J. Cardoso, and J. Fernandes, Transfer Learning with Partial Observability Applied to Cervical Cancer Screening. Springer International publishing AG, 2017.

[19] M. Darwish-Yassine et al., "An assessment of gynecological cytology screening practices among health care providers nationwide," Arch. Pathol. Lab. Med., vol. 139, no. 5, pp. 650-655, 2015.

[20] R. Catarino, "Cervical cancer screening in developing countries at a crossroad: Emerging technologies and policy choices," World J. Clin. Oncol., vol. 6, no. 6, p. 281, 2015.

[21] J.-B. Lew, K. Simms, M. Smith, H. Lewis, H. Neal, and K. Canfell, "Effectiveness Modelling and Economic Evaluation of Primary HPV Screening for Cervical Cancer Prevention in New Zealand," PLoS One, vol. 11, no. 5, p. e0151619, 2016.

[22] N. G. Campos, M. Sharma, A. Clark, J. J. Kim, and S. C. Resch, "Resources required for cervical cancer prevention in low- and middle-income countries," PLoS One, vol. 11, no. 10, pp. 1-20, 2016.

[23] M. R. Hasan, H. Gholamhosseini, and N. I. Sarkar, "A new ensemble model for multivariate medical data," in International Telecommunication networks and applications conference, 2017 (in press). 